\title{
VOCÊ TEM QUE SE DECIDIR: a árvore ou o PIB?'
}

\author{
Devinder Sharma
}

\section{O “CHOMSKY VERDE" NÃO POUPA PALA- VRAS PARA ALERTAR SOBRE A CRISE INVISÍVEL DA FOME}

Claro e incisivo em suas opiniões, Devinder Sharma é o tipo de entrevistado que coloca o editor numa situação complicada. Pinçar o mais importante entre tantas colocações cruciais torna-se um desafio técnico.

Devinder Sharma, 55 anos, é jornalista, escrevendo e mantendo colunas em um punhado de jornais editados em diferentes línguas indianas -e frequentemente é solicitado para foros de debate e entrevistas, inclusive pela rede americana CNN. Sharma mantêm seu blog "Ground Reality", Realidade Nua e Crua, numa tradução livre, focado no

* Mestre em Genética e Melhoramento de Plantas. Pesquisador e jornalista de investigação sobre questões políticas relativas à agricultura sustentável, biodiversidade e os direitos de propriedade intelectual, meio ambiente e desenvolvimento, segurança alimentar e biotecnologia, a pobreza e a fome, e as implicações do paradigma do livre comércio para os países em desenvolvimento. http://devinder-sharma.blogspot.com

${ }^{1}$ Entrevistado, em setembro de 2010, por Eduardo Almeida, jornalista, indigenista e agricultor. Dirigente e Conselheiro da ANAÍ. almeidaedu@uol.com.br debate sobre políticas para alimentação, agricultura e fome-http://devinder-sharma.blogspot.com/- visitado por dezenas de milhares de internautas em todo o mundo, sobretudo formadores de opinião.

Sharma mora em Nova Delhi, onde dirige uma iniciativa independente chamada Foro para Biotecnologia e Segurança Alimentar. Se autodefine como um "analista sobre políticas para alimentação e comércio”. Tem formação agronômica e é reconhecido como estudioso e pensador sobre o desenvolvimento, a sustentabilidade e a fome, tema de livros que tem publicado. Chomsky Verde foi o apelido que ganhou do semanário indiano The Week no ano passado, pela similaridade de sua postura crítica ampla e aguda com a do famoso linguista e pensador americano Noam Chomsky. Devinder Sharma ainda encontra tempo para constantes visitas e debates em comunidades rurais de seu país.

A passagem recente pelo Brasil aprofundou sua análise sobre o país. As conclusões são pouco lisonjeiras. Confessa-se "assombrado diante do modo como as empresas de agronegócio, incluindo gigantes internacionais, controlam a economia bra- 
sileira” e sem entender como o Brasil, com todo o "vasto celeiro de biodiversidade e riqueza genética que possui", prefere um modelo de desenvolvimento rural que "marginaliza as comunidades rurais e deixa rastros profundos de destruição ecológica".

Em tempos de crise financeira mundial e emergências globais, Sharma denuncia o aumento da fome no Mundo e acentua o protagonismo popular na superação das crises, lembrando Ghandi - "ele nos disse que se faz necessário um sistema de produção pelas massas e não para as massas”. Não faz por menos, detona, em série, os modelos atuais de desenvolvimento: "a 'economia do crescimento' que as economias emergentes perseguem é, na realidade, nada mais que economia da violência"; o endeusamento do PIB, "é uma cortina de fumaça para que o rico explore o pobre”; o capitalismo wallstreetiano, "levará o mundo na direção da extinção da espécie humana" e a democracia tal como se apresenta hoje no mundo; critica a ONU e ainda sobra para os economistas.

Apresentado por colega comum de rede de discussão ao jornalista free lancer baiano Eduardo Almeida (almeidaedu@uol.com.br),Sharma concedeu a entrevista pela internet.

Eduardo Almeida - O Sr. esteve por sete dias no Brasil recentemente. Esse país tem estado em evidência em temas contraditórios que são objeto de suas preocupações: a luta contra a fome e o agronegócio de grande escala com elevado apetite por desmatamento e organismos geneticamente modificados (OGMs). O que mais lhe chamou a atenção no Brasil?

Devinder Sharma - Eu vim ao Brasil a convite da AS-PTA [ONG brasileira dedicada a agroecologia e agricultura familiar] para participar de uma conferência internacional, no Rio de Janeiro, sobre alimentos e lavouras geneticamente modificados. A conferência congregou ativistas, especialistas, ONGs, representantes governamentais e de organizações de produtores da Índia, Brasil e África do Sul-nações que formam o IBSA-, além de outros países. Em certo sentido, o evento foi focado em fortalecer o movimento antitransgênicos no Brasil. Sabendo que o Brasil vem adotando crescentemente lavouras geneticamente modificadas, e já tomou o lugar da Argentina como país com maior área de lavouras GM [geneticamente modificadas] na América do Sul, foi importante ter uma compreensão, em primeira mão, das razões que estão por trás dessa crescente difusão das lavouras GM, e, ao mesmo tempo, conhecer a luta das pessoas contra esse tipo de agricultura.

Além disso, na semana em que estive no Brasil, eu busquei informações sobre duas outras áreas de meu interesse. Uma se relaciona ao Programa Fome Zero, que o Presidente Lula lançou entre 2003 e 2004, e a outra diz respeito à formidável reviravolta que o Brasil realizou em desenvolver gado puro de algumas raças indianas e ainda se tornando importante exportador dessas raças para a América Latina, África e Ásia. Essas raças bovinas proporcionam rendimentos em leite comparáveis às raças Jersey e holandesa, enquanto suas primas pobres na Índia são tachadas de "improdutivas", com capacidade de produção de leite muito baixa.

EA - As crescentes ações do Brasil em outros países tropicais, especialmente da África e América Latina, difundem tecnologias para produções de grãos e carne em larga escala, ao estilo "revolução verde", em pacotes que frequentemente incluem transgênicos, química pesada e pouco cuidado com o meio-ambiente. O Sr. acha que a dita "estória de sucesso do moderno agronegócio brasileiro" é um bom espelho para países tropicais em desenvolvimento?

DS - Este é um motivo para grave inquietação. A guinada deliberada do Brasil, de uma agricultura sustentável, utilizando o vasto celeiro de biodiversidade e riqueza genética que possui, para a agricultura industrial, que é ecologicamente destrutiva e leva ao aquecimento global, vem não apenas resultando na marginalização das comunidades rurais como também deixando rastros profundos de destruição ecológica, cujos custos serão assumidos pelas gerações futuras. A dívida ecológica que o Brasil tem criado no processo supera o ganho econômico de curto prazo a que ele visa. Como não há jeito de medir o rastro de destruição 
ecológica em termos econômicos, o Brasil parece inteiramente despreocupado.

Eu fico assombrado diante do modo como as empresas de agronegócio, incluindo gigantes internacionais, controlam a economia brasileira. $\mathrm{O}$ agribusiness prospera na destruição das florestas originais, no envenenamento dos solos, minando as águas subterrâneas e contaminando a cadeia alimentar. Estudos recentes evidenciam que os pequenos produtores são os mais atingidos, e acabam migrando em massa para as cidades. Não obstante, o Ministro da Agricultura, assim como o do [da Indústria e] Comércio, parecem simplesmente facilitar a encampação empresarial da agricultura e, assim, almejam políticas agrícolas e comerciais que não projetam nem protegem os interesses de produtores e do meio de vida não apenas do Brasil mas também de outros países em desenvolvimento.

EA - Que papel o Sr. espera que Estados Democráticos, como a Índia e o Brasil, podem desempenhar na construção de uma Nova Ordem Mundial livre da fome, com agricultura sustentável, respeito pela biodiversidade, com justiça social e comércio justo? Sendo o seu país considerado a maior democracia do Mundo e tendo o Sr. uma abordagem crítica sobre a relutância do Governo Indiano em prevenir situações de opressão social, qual o problema com a Democracia? Falhando em garantir poder real ao povo em tantos países, deve a Democracia ser aprofundada e redesenhada?

DS - Houve um tempo em que Abrahão Lincoln afirmou que "a democracia é o governo do povo, pelo povo e para o povo". Hoje, as propaladas democracias ao redor do mundo, incluindo a Índia, o Brasil e os Estados Unidos, tornaram-se "da indústria, pela indústria e para a indústria”. Gigantes democráticos do mundo em desenvolvimento - Brasil, Índia, África do Sul estão ocupados criando uma nova ordem mundial onde o interesse empresarial reine supremo. Os governos em todos esses países perderam o contato com as massas e seguem um modelo econômico que não enxerga além de negócios, comércio e indústria.
Na Índia, que reivindica o título de maior democracia do mundo, não há justificativa plausível para o fato de que um terço da população de 1,2 bilhões esteja vivendo com fome. Com quase $47 \%$ das crianças com idade inferior a seis anos subnutridas, e com $55 \%$ da população classificada pelo PNUD [Programa das Nações Unidas para o Desenvolvimento] como afetada pela pobreza, a Índia projeta-se a si mesma como uma super potencia emergente. Nos anos recentes, desde que a Índia se antecipou na liberalização econômica, as disparidades econômicas têm apenas aumentado. Os ricos se tornaram mais ricos e os pobres vêm sendo empurrados contra a parede. O gradual apossamento dos recursos naturais pela indústria tem criado um sentimento de desesperança entre as comunidades tribais. $\mathrm{O}$ aprofundamento da desconfiança, entre os mais pobres das regiões mais pobres do país, em relação às políticas de governo é tal ordem, que quase um terço do país, mormente o rico cinturão mineral [Estados do Nordeste e Centro-Norte da Índia], enfrenta rebeliões lideradas pelos Maoístas.

Eu me admiro como a Índia pode ser uma orgulhosa democracia, se sucessivos governos têm falhado em satisfazer às aspirações da maioria da população. Como fome e pobreza podem existir em escala tão dramática numa democracia? A projeção do crescimento econômico, na qual se reivindica ter a segunda maior taxa de crescimento econômico, pouco se espelha nas realidades. Os governos perderam o contato com as massas, e o poder real está nas mãos do empresariado. Tanto é assim que a maioria dos representantes populares eleitos para o Parlamento agora são milionários. Você não pode vencer uma eleição se você não for rico. A verdadeira essência da democracia, consequentemente, se perdeu. A democracia se tornou uma "empresariocracia". Acredito fortemente que é chegado o tempo de uma revisão sobre o significado de democracia. Na medida em que se submetem ao controle empresarial, as democracias perdem essência e comprometem o papel para o qual foram concebidas por nossos antepassados. Quero dizer, o mundo dos negócios, cer- 
tamente, não vai nos propiciar equidade e justiça.

EA-O Sr. tem sustentado que os mercados de capitais são os principais protagonistas do esgotamento dos recursos naturais em escala planetária e da manutenção da fome e da injustiça. O neoliberalismo disseminou a ideia de que o capitalismo ainda é o grande propulsor do desenvolvimento e, de fato, países emergentes, como Índia, China e Brasil, têm crescido a altas taxas em parte devido a grandes influxos de capital. O Sr. acredita em caminhos alternativos ao desenvolvimento que beneficiem as maiorias e minorias excluídas, de modo social e ambientalmente sustentável?

DS - Não há outra inovação - se você não gosta do termo invenção-nos tempos recentes, que não apenas influenciou mas acelerou o processo do consumo desenfreado, a não ser a emergência de Wall Street. De fato, os economistas podem se recusar a aceitar isso agora e por razões obvias, mas os mercados de capitais levarão o mundo na direção da extinção da espécie humana, como nos alertou o cientista australiano Frank Fenner.

Eu fico impressionado com a maneira como opera o mercado de capitais. Esses mercados transformaram tudo em commodity. Grande parte dos males ambientais do mundo é consequência direta do mercado de capitais. Os mercados de capitais sugarão cada gota d'água - ou outro recurso natural - do planeta. Há um preço para tudo, incluindo o ar que você respira.

A 'economia do crescimento' que as economias emergentes perseguem é, na realidade, nada mais que a economia da violência. Ela desencadeia violência contra os recursos naturais, contra o clima, contra a natureza e também contra o próximo, o ser humano. Ela retira os recursos naturais, físicos e também financeiros das mãos dos pobres para os bolsos dos ricos e das elites. Nos é dito, frequentemente, que os $20 \%$ de providos da população mundial controlam e usam os recursos dos $80 \%$ dos desprovidos. A globalização reforça ainda mais esse monopólio e amplia as disparidades já existentes. Tira recursos das mãos dos pobres para adicionar à fortuna dos ricos.

EA - Muitos pensadores e economistas de sensibilidade social têm argumentado que é inevitável primeiro alavancaro PIB por todos os meios e somente depois implementar políticas de distribuição de rendas. Como o Sr. concebe o desenvolvimento no quadro internacional atual?

DS - Os economistas são uma raça esperta. Eles conceberam o PIB como um indicador de crescimento. Eles o moldaram com tanta destreza que nós aceitamos um indicador de riqueza pessoal como um ponteiro para o desenvolvimento nacional. Quanta ilusão de crescimento eles criaram! Eles fizeram com que tudo, incluindo o clima global, se pareça com uma commodity a ser vendida e explorada. Quanto mais você explora mais o PIB sobe. Você pode destruir um país numa guerra, e então você o reconstrói, o PIB se eleva. Isso é o que aconteceu com o Iraque.

O PIB, para o leigo, significa o montante de dinheiro que troca de mãos. Se você compra um carro, o PIB sobe. Se você corta uma árvore, o PIB sobe. Mas se você preserva a árvore, o PIB pode não crescer. Agora você tem de decidir se você precisa da árvore ou do PIB.

Se você visualizar globalmente, o aumento no PIB não tem levado a desenvolvimento integral. Mesmo nos Estados Unidos, o país mais rico do mundo, a fome quebrou um recorde de 14 anos. Hoje, uma em cada 10 pessoas passa fome. A menos que a gente reverta essa prescrição deformada de crescimento econômico, nós nunca teremos a renda sendo distribuída razoavelmente em qualquer população. Vale lembrar, o PIB não é a pedra de toque do desenvolvimento. Ele é uma cortina de fumaça para que o rico explore o pobre.

EA - No contexto da atual crise econômica e seu impacto sobre a agricultura e a segurança alimentar, que diretrizes e abordagens, em sua opinião, devem ser adotadas por países em desenvolvimento no sentido de prevenir desastres e retomaro desenvolvimento social sustentável?

DS - O colapso econômico atual trouxe globalmente US\$ 20 trilhões em pacotes de ajuda. Esses pacotes beneficiaram bancos e firmas de investimento que, na verdade, deveriam ter sido penalizadas por levar a economia mundial à beira 
do precipício. Ao invés disso, eles receberam aplausos e honrarias pelo crime econômico que cometeram com toda impunidade.

A questão que precisa ser colocada é: por que o mundo injetou tanto dinheiro em bancos e empresas de investimento? A resposta é de que o objetivo é de manter o fluxo financeiro, o que permitirá aos governos manter o ritmo do crescimento econômico. Eu tenho perguntado constantemente onde está o objetivo subjacente dessa generosidade. A resposta que obtenho é de que o objetivo é reduzir a fome e a pobreza, ao proporcionar oportunidade de renda e meios de vida. Se não há crescimento, não haverá oportunidades para criação de meios de vida. Isso é certamente divertido, com jeito de arrogância intelectual beirando a estupidez.

O que está sendo camuflado é que o mundo necessita apenas US\$ 1 trilhão para eliminar a fome, as doenças e a pobreza da face do planeta. Nós não temos dinheiro para isso. Mas nós temos US\$ 20 trilhões para socorrer os corruptos e escroques dos negócios e da indústria.

EA - Superar as barreiras políticas, econômicas e ideológicas estruturais ao desenvolvimento social e sustentável, incluindo zerar a fome, certamente não é tarefa fácil. Como poderemos lidar, nessa luta, com os desafios extras representados pelas chamadas emergências globais, como aquecimento global, mudanças climáticas, perda de biodiversidade e crise energética?

DS - As barreiras estruturais ao desenvolvimento social e sustentável, incluindo combater a fome, estão, na verdade, entremeadas nas políticas neoliberais equivocadas. Os desafios extras das mudanças climáticas, aquecimento global, perda de biodiversidade e da sempre crescente crise energética são também resultados do paradigma do crescimento.

Deixe-me fazer uma pergunta. Se a prescrição econômica para a economia global que o mundo vem seguindo é tão boa, por favor, me diga por que o mundo chegou a essa beira de precipício? Por que os recursos naturais do planeta foram poluídos e pilhados? Por que os rios estão fluindo sujos, e por que as fontes de água limpa estão todas secando? Por que a biodiversidade tem desa- parecido a um ritmo tão alarmante, trazendo o mundo mais próximo da extinção? Por que motivo o IPCC (Painel Intergovernamental sobre Mudanças Climáticas, promovido pela ONU) chega ao ponto de nos alertar que, se não procedermos a uma mudança radical no modo em que o mundo progride, não haverá tempo suficiente para evitar um colapso da população humana? Essa é uma clara denúncia das políticas econômicas que o mundo foi levado a seguir. As emergências que você menciona são o resultado de um pensamento econômico grosseiramente falho.

A resposta está no que Mahatma Gandhi nos falou. Ele disse que a Terra tem suficiente para a necessidade de cada um, mas não para a ganância. Ele também nos disse que se faz necessário um sistema de produção pelas massas e não para as massas. Esse, em essência, é o fundamento do conceito de soberania alimentar de que a sociedade civil fala. Ao invés de fomentar o livre comércio, usando a OMC [Organização Mundial do Comércio] como agente policial para basicamente disponibilizar mercado para a produção agrícola altamente subsidiada dos países da OCDE [Organização de Cooperação e Desenvolvimento Econômico, ou "Clube dos Países Ricos"], o mundo deve voltar-se ao atendimento da autossuficiência alimentar. Tornar os países dependentes de importações de alimentos é uma receita para o desastre, mas certamente soma para o PIB e, o que não é dito, quanto mais comércio, mais aquecimento global. Contudo, você se surpreenderá em saber que, nos últimos 30 e poucos anos, desde que o Banco Mundial e o FMI começaram os programas de ajustes estruturais, 105 dos cerca de 149 países do Terceiro Mundo se tornaram importadores de alimentos. Se a Rodada de Doha, da forma como tem sido concebida, chega a uma conclusão em breve, escreva o que estou dizendo, o restante dos países do Terceiro Mundo também se tornarão importadores de alimentos a qualquer momento. E não se esqueça: importar alimentos é como importar desemprego. Os alimentos se tornarão, então, a mais forte das armas políticas.

EA - Como o Sr. avalia o papel exercido 
pelas Nações Unidas e seu Sistema (PNUD, FAO e outras) no esforço para enfrentar os principais problemas da Humanidade? A ONU estabeleceu os ODM - Objetivos do Milênio - a serem atingidos em 2015. Isso irá funcionar?

DS - Os Objetivos do Milênio não vão dar certo. Lembro que, quando a Cúpula Mundial sobre Alimentação, em 1996 [em Roma], anunciou que é criminoso observar 24.000 pessoas sucumbindo ante a fome todos os dias, e os dirigentes internacionais manifestavam urgência no enfrentamento da fome, prometendo reduzir em $50 \%$ os estimados 842 milhões de pessoas famintas até 2015, eu reagi com choque e desgosto. Eu então disse que isso é um caso clássico de desonestidade política.

Pelo tempo que o Mundo promete reduzir à metade o número de famintos, considerando que 24.000 pessoas morrem de fome todos os dias, em algum lugar, 128 milhões de pessoas podem ter sucumbido apenas pela fome. Como isso pode ser classificado como emergência? Não seria isso um crime contra a Humanidade?

Os ODM meramente reiteraram a promessa da Cúpula Mundial sobre a Alimentação. E, como sabemos hoje, o número de famintos, na verdade, aumentou: de 842 milhões em 1996 para 1.1 bilhão em 2010. A ONU pode, com certeza, se vangloriar, se mostrar satisfeita com sua 'grande' missão humanitária. Mas a realidade é que a ONU não é nada melhor que o Banco Mundial. A linha fronteiriça entre a ONU e o Banco Mundial foi borrada com o passar dos anos.

EA-Quais as suas visões sobre Cooperação Sul-Sul? Países como Índia e Brasil compartilham condições similares em muitos aspectos, mas continuam mantendo relativamente fracos comércio e intercâmbio técnico-científico. Velhos vínculos Norte-Sul, heranças estruturais do colonialismo, parecem colidir com a perspectiva de os países do Terceiro Mundo se associarem no enfrentamento de desafios comuns. O que o Sr. acha que Índia e Brasil poderiam fazer em conjunto pelo avanço da luta contra a fome e pelo desenvolvimento sustentável em seus respectivos países e em outros?
DS - Cooperação Sul-Sul soa agradável. Os acadêmicos têm usado isso em resposta ao "fator NHA” (não há alternativa). Eu sempre acho graça quando ouço falar em cooperação Sul-Sul. Eu não conheço nenhum país do Sul que não almeje imitar o Norte. O que quer que os líderes políticos possam dizer, eles se sentem honrados quando convidados a se alinhar para a foto nas cúpulas do G20. Os acadêmicos fazem o mesmo; os economistas, claro, extrapolam. Se você observa os currículos, lá está a menção orgulhosa de universidades do Norte que eles visitaram ou onde realizaram trabalhos.

Mesmo quando o Presidente Lula e o Primeiro-Ministro Manmohan Singh falam em colaboração bilateral, no mais das vezes é para promover o mesmo sistema que eles tomam emprestado dos países ocidentais. Na verdade, a cooperação Sul-Sul, quando existe, é construída sobre os mesmos princípios de exploração. O 'big brother' faz exatamente o mesmo, com seu primo menor, que os Estados Unidos faz com a Índia e o Brasil.

Isso não significa que a cooperação Sul-Sul não seja possível. Tudo que ela precisa como ponto de partida é confiança e respeito. Isso só é possível se o líder do país mais desenvolvido exibir estadismo político e se abstiver do papel de peixe grande que come o peixe menor. Tenhamos esperança de que, algum dia, alguém mostre sagacidade política e uma nova ordem possa então surgir.

A título de exemplo, está sendo anunciado, na África, um programa ambicioso, o AGRA - Aliança para a Revolução Verde na África [Alliance for Green Revolution in Africa], com o objetivo de incrementar a produção agrícola. Kofi Annan [exSecretário Geral da ONU] está à frente dessa iniciativa. Lamentavelmente, esse programa é baseado em agricultura industrial e incentiva o domínio empresarial da agricultura. A AGRA não é o que a África precisa. Nesse caso, melhor teria sido a África buscar cooperação Sul-Sul com países em desenvolvimento, apostando em sistemas agrícolas que não matam os agricultores. A África precisaria aprender as lições do fiasco da revolução verde na Índia. Mais de 200 mil camponeses cometeram suicídio nos últimos 15 anos na Índia, essencial- 
mente porque a equação da revolução verde deu errado. Estou certo de que os líderes africanos não desejam que seus camponeses morram. Portanto, a África não precisa da AGRA, mas sim da 'SAGRA' - Sustainable Agriculture for Africa - Agricultura Sustentável para a África.

EA - No começo de setembro (2010) Moçambique foi palco de agitações populares. Sete pessoas foram mortas quando manifestantes se mostraram inconformados com o aumento do preço do pão. O Sr. acha que isso pode indicar uma nova crise de alimentos mundial como se esboçou em 2007-2008?

DS - As manifestações por comida em Moçambique e as crescentes tensões no Paquistão, Egito e Rússia siberiana por causa da espiral altista de preços de alimentos evidenciam a crise mundial de alimentos e suas vulnerabilidades. Apesar de a FAO-ONU mostrar preocupações - mas não o receio de repetição da crise de 2007-2008 -, não se vê nenhuma iniciativa em superar os desequilíbrios do sistema de gerenciamento dos alimentos que ocasionam a crise. Enquanto o mundo assiste a agitações populares por alimentos em 37 países, os estoques de grãos de empresas multinacionais e de tradings deram um salto.
Não se vê nenhum aprendizado com a débâcle que aconteceu em 2007-2008. Na verdade, o G-20 tem encorajado uma repetição do problema. Ele tem orientado seus países membros a removerem tudo que impeça investimentos estrangeiros diretos em varejo de alimentos e, ao mesmo tempo, pressiona agressivamente os países em desenvolvimento a removerem todas as barreiras comerciais nos Acordos de Livre Comércio e outros tratados regionais. Os países em desenvolvimento, portanto, têm se tornado cada vez mais importadores de alimentos. Observemos que Moçambique teve suas manifestações populares quando a Rússia impôs proibição à exportação de trigo por mais um ano após uma seca severa e incêndios no campo.

O que aconteceu em Moçambique, nesse setembro, é algo que pode se repetir em qualquer lugar nos anos vindouros. A menos que o Mundo incentive os países em desenvolvimento e os menos desenvolvidos a se tornarem autossuficientes em grãos alimentares, a ameaça iminente de distúrbios continuará sobre a cabeça das nações, como espadas de Dâmocles. Entretanto, como o assunto afeta os interesses dos gigantes do agronegócio, o G20 prefere encarar de outra maneira.

(Recebido para publicação em outubroo de 2010) (Aceito em dezembro de 2010)

Devinder Sharma - Indiano, Mestre em Genética e Melhoramento de Plantas. Pesquisador e jornalista de investigação sobre questões políticas relativas à agricultura sustentável, biodiversidade e os direitos de propriedade intelectual, meio ambiente e desenvolvimento, segurança alimentar e biotecnologia, a pobreza ea fome, e as implicações do paradigma do livre comércio para os países em desenvolvimento.

Recentemente foi agraciado com o título honorário de professor at Large pela Himachal Pradesh Agricultural University CSK, Palampur (Índia), onde se formou.

Está associado a inúmeras organizações nacionais e internacionais, grupos da sociedade civil e organizações de agricultores e é membro do CGIAR Central de Assessoria em Propriedade Intelectual. Entre seus trabalhos mais recentes incluem, quatro livros: GATT e da Índia: a política da agricultura; GATT à OMC: Seeds of Despair; No Trap Fome; Bhhokh ka Asli Chehra. 